\title{
Elevated white cell count in acute coronary syndromes: relationship to variants in inflammatory and thrombotic genes Connie E Byrne ${ }^{\dagger 1,3}$, Anthony Fitzgerald ${ }^{\dagger 2,3}$, Christopher P Cannon ${ }^{4}$, Desmond J Fitzgerald ${ }^{1,3}$ and Denis C Shields*1,3,5
}

\author{
Address: ${ }^{1}$ Department of Clinical Pharmacology, Royal College of Surgeons in Ireland, 123 St Stephen's Green, Dublin 2, Ireland, ${ }^{2}$ Department of \\ Epidemiology, Royal College of Surgeons in Ireland, 123 St Stephen's Green, Dublin 2, Ireland, 3Institute of Biopharmaceutical Sciences, Royal \\ College of Surgeons in Ireland, 123 St Stephen's Green, Dublin 2, Ireland, ${ }^{4}$ TIMI Study Group, Cardiovascular Division, Brigham and Women's \\ Hospital and Harvard Medical School, Boston, MA USA and ${ }^{5}$ Surgen Ltd., Royal College of Surgeons in Ireland, 123 St Stephen's Green, Dublin \\ 2, Ireland \\ Email: Connie E Byrne - cbyrne@rcsi.ie; Anthony Fitzgerald - tfitzgerald@haughton-institute.ie; \\ Christopher P Cannon - cpcannon@partners.org; Desmond J Fitzgerald - dfitzgerald@rcsi.ie; Denis C Shields* - dshields@rcsi.ie \\ * Corresponding author †Equal contributors
}

Published: 01 June 2004

BMC Medical Genetics 2004, 5:13
Received: 15 May 2003

Accepted: 0 I June 2004

This article is available from: http://www.biomedcentral.com/I47I-2350/5/I3

(c) 2004 Byrne et al; licensee BioMed Central Ltd. This is an Open Access article: verbatim copying and redistribution of this article are permitted in all media for any purpose, provided this notice is preserved along with the article's original URL.

\begin{abstract}
Background: Elevated white blood cell counts (WBC) in acute coronary syndromes (ACS) increase the risk of recurrent events, but it is not known if this is exacerbated by pro-inflammatory factors. We sought to identify whether pro-inflammatory genetic variants contributed to alterations in WBC and C-reactive protein (CRP) in an ACS population.
\end{abstract}

Methods: WBC and genotype of interleukin 6 (IL-6 G-174C) and of interleukin-I receptor antagonist (ILIRN intronic repeat polymorphism) were investigated in 732 Caucasian patients with ACS in the OPUS-TIMI- 16 trial. Samples for measurement of WBC and inflammatory factors were taken at baseline, i.e. Within 72 hours of an acute myocardial infarction or an unstable angina event.

Results: An increased white blood cell count (WBC) was associated with an increased C-reactive protein $(r=0.23, p<0.001)$ and there was also a positive correlation between levels of $\beta$ fibrinogen and C-reactive protein $(r=0.42, p<0.000 I)$. ILIRN and IL6 genotypes had no significant impact upon WBC. The difference in median WBC between the two homozygote IL6 genotypes was $0.2 \mathrm{I} / \mathrm{mm}^{3}(95 \% \mathrm{Cl}=-0.4 \mathrm{I}, 0.77)$, and $-0.03 / \mathrm{mm}^{3}(95 \% \mathrm{Cl}=-0.55,0.86)$ for ILIRN. Moreover, the composite endpoint was not significantly affected by an interaction between WBC and the ILI $(p=0.61)$ or IL6 $(p=0.48)$ genotype.

Conclusions: Cytokine pro-inflammatory genetic variants do not influence the increased inflammatory profile of ACS patients.

\section{Background}

There is compelling evidence that systemic inflammation plays a role in the development and progression of coro- nary heart disease (CHD) [1]. White blood cell (WBC) counts are elevated in patients presenting with acute coronary syndromes. Early studies have shown that patients 
with elevated white blood cell (WBC) counts were at higher risk of mortality and recurrent AMI [2,3]. More recent studies have confirmed the association between an elevated WBC and clinical outcomes in AMI patients and furthermore suggested that WBC could serve as a simple and inexpensive tool for risk stratification in acute coronary syndromes $[4,5]$.

The pro-inflammatory cytokines IL-1 and IL- 6 have also been implicated in several mechanisms that contribute to the development of CHD and increased levels of IL- 6 are associated with higher cardiovascular mortality [6]. Proinflammatory cytokines stimulate the liver to synthesize acute phase proteins, which in turn are associated with a higher risk of cardiovascular events [6]. For example, Creactive protein (CRP) whose concentration in serum is increased in response to inflammatory stimuli is also elevated in ACS compared to stable angina or vasospastic angina [7-9]. Elevated CRP is associated with increased cardiac morbidity [10-12]. Increased levels of fibrinogen, another acute phase protein are a strong predictor of a poor outcome in unstable CAD, and are also reported in patients with asymptomatic atherosclerosis [13-15]. Similarly, plasma vWF levels are strongly associated with ischaemic heart and cerebrovascular disease [16]. Thus, a variety of inflammation markers are risk factors for myocardial infarction and other acute coronary syndromes [17-19]. Inflammatory proteins may not only be markers of disease but may contribute to its pathogenesis. For example, there is evidence that CRP and fibrinogen promote vascular inflammation and thrombosis $[18,20]$.

In spite of the mounting evidence implicating a group of inflammation-related markers and coronary disease, the mechanisms are still poorly understood. While inflammation in the vessel wall may be a consequence of environmental factors (infection, tissue injury), it is also possible that genetic factors contribute to an abnormal or exaggerated inflammatory response. Moreover, interactions between inflammatory markers and variants of thrombotic genes may contribute to the coronary thrombosis that underlies ACS. We sought to determine whether the elevated white cell count in ACS is influenced by proinflammatory genetic variants.

The IL1 chromosomal cluster of genes contains an extended haplotype spanning the IL1beta and IL1RN genes [21]. This haplotype is represented by the IL1RN intronic repeat $* 2$ allele [22]. Carriers of $* 2$ appears to be over-represented in some diseases associated with inflammation [21,23-25]. IL1 Receptor Antagonist levels are elevated in acute MI, but it is unclear whether the $* 2$ allele carriers have an altered risk of cardiovascular disease [2628]. The role of the IL1 cluster haplotype in modulating WBC levels in coronary patients has not been investigated, and we wished to determine if cardiovascular patients carrying * 2 had an elevated WBC. The IL6 promoter variant $174 \mathrm{G}$ allele is associated with higher levels of acute phase IL6, with heterozygotes intermediate between the two homozygotes [29]. The G allele is associated with both arthritis and susceptibility to Kaposi sarcoma and has been associated with atherosclerosis [30-32]. We wished to evaluate whether there the IL6-174GG genotype was associated with higher WBC than the -174CC genotype.

The hypothesis we wished to test was whether or not the elevated WBC seen in patients with an acute event is elevated in carriers of pro-inflammatory genetic variants. In the absence of careful studies of WBC before and after an acute event, the pathophysiological causation of elevated WBC in patients that presented with $\mathrm{MI}$ is incompletely understood. The impact of myocardial damage, and inflammatory states prior to the MI, are likely to be two important factors, although extent of ischaemia was not shown to be strongly associated with WBC in another study [5]. It is unclear if inflammatory responses associated with IL1 and IL6 cytokines are key to modulating either of these processes. From a clinical perspective, identifying any association between pro-inflammatory variants and WBC (resulting from either process, and regardless of cause) could provide a perspective on the anti-inflammatory mechanisms that may be relevant in improving patient prognosis. Additionally, we examined the relationship of the pro-inflammatory variants with CRP, another marker of inflammation, and with variants in thrombotic genes previously implicated in coronary thrombosis.

In order to test this hypothesis, baseline white cell counts around the time of presentation were investigated from two clinical trial studies (sample sizes of patients with white cell counts at follow-up were not sufficient to permit a powerful test of such effects at later time points). The first study was the multinational OPUS-TIMI 16 study [33]. Patients had to have either acute myocardial infarction or unstable angina, with an associated high-risk feature, and be enrolled within 72 hours from the onset of their acute coronary syndrome. For comparison purposes, a group of patients with acute myocardial infarction or unstable angina from the EXCITE trial (who were recruited at the time of a percutaneous intervention, and therefore are mainly outside the time period of an acute event) and a group of patients presenting with stable angina (also from the EXCITE study) were similarly examined [34]. 


\section{Methods \\ Study population \\ OPUS TIMI-1 6 trial}

This was the main population for this study. 924 Caucasian patients were recruited within the genetics sub-study from the OPUS-TIMI 16 trial of the oral platelet glycoprotein IIb/IIIa antagonist Orbofiban [33]. Patients were recruited from 888 hospitals in 29 countries around the world. Patients received aspirin and were randomised to receive: (A) $50 \mathrm{mg}$ of orbofiban daily, (B) $50 \mathrm{mg}$ of orbofiban twice daily for 30 days followed by $30 \mathrm{mg}$ orbofiban twice daily, or (C) a placebo. The primary composite endpoint was myocardial infarction, recurrent ischaemia requiring rehospitilisation, urgent revascularisation, stroke and/or death. Inclusion criteria for OPUS trial: patients with acute coronary syndromes defined as ischaemic chest pain at rest within 72 hours of randomisation, associated with positive cardiac markers, electrocardiographic changes, or prior cardiovascular disease.

602 of the patients presented with MI and 412 with unstable angina. WBC count and platelet count data at baseline were available for 732 patients. C-reactive protein and fibrinogen levels were measured in 297 OPUS TIMI-16 patients.

\section{EXCITE trial}

This second study population was studied in order to determine if any suggestive findings in the OPUS study were confirmed in coronary patients recruited with stable angina or ACS outside the immediate time of the acute event. 531 patients were recruited for the genetics substudy from the EXCITE (Evaluation of oral Xemilofiban In Controlling Thrombotic Events) trial of the oral platelet glycoprotein IIb/IIIa antagonist Xemilofiban [34]. This phase 3 trial was a double-blind, randomised, placebocontrolled study conducted at 412 centers in North and South America, New Zealand, Europe, Israel, Australia, and South Africa. Patients were enrolled who had angiographic evidence of clinically significant coronary artery disease necessitating PTCR. 342 of the subjects presented with stable angina (SA) while the remainder presented with ACS (44 MI, 145 unstable angina).

\section{Genotyping, cell counts and biochemical assays}

The plasma component was frozen and shipped on dry ice to Children's Hospital (Boston), where samples were stored at $-70^{\circ} \mathrm{C}$. CRP was measured by ELISA (N Latex CRP assay, Dade Behring, Newark, DE) close to the time of the index coronary event, at the time of recruitment. Agarose gel sizing was used to determine the genotype of variable number tandem repeat (VNTR) in IL1RN, using the PCR amplification primers previously described [22]. IL-6 genotyping was performed by restriction enzyme digestion [35]. Genomic DNA amplifications were carried out in $50 \mu \mathrm{l}$ reactions containing $50 \mathrm{ng}$ DNA, $1 \mathrm{mM}$ dNTPs, $1.5 \mathrm{mM} \mathrm{MgCl}_{2}$, 10X Taq polymerase buffer, 1 unit Taq polymerase enzyme, 10 pmoles each of sense (5' ACCTAAGCTGCACTTTTC $3^{\prime}$ ) and antisense primers (5' ATTTATTGGGGGTTGAG 3'). Amplification consisted of an initial denaturation step of $94^{\circ} \mathrm{C}$ for 5 minutes, followed by 30 cycles of denaturing at $94^{\circ} \mathrm{C}$ for 1 minute, annealing $55^{\circ} \mathrm{C}$ for $1 \mathrm{~min}$, and elongating at $72^{\circ} \mathrm{C}$ for 1 minute. PCR product was verified by $2 \%$ TBE agarose gel electrophoresis, stained with ethidium bromide and visualised under ultra-violet (UV) light. Restriction digests were set up in $40 \mu \mathrm{l}$ reactions containing 10-20 $\mu \mathrm{l}$ PCR product, 10X restriction enzyme buffer, 0.5-7.5 units of restriction enzyme (Hsp92 II) and BSA. The reactions were incubated at $37^{\circ} \mathrm{C}$ overnight. Digests were verified on $2 \%$ TBE agarose gels, stained with ethidium bromide and visualised under UV light. Other genotypes were determined according to methods described elsewhere, evaluating the following genetic variants: GPIIIa PLA2, GPIb $\alpha-5 \mathrm{C}$, GPIa 807T, E-selectin 128C, P-selectin 715C, vWF-1051 G, MMP9-1562T, and $\beta$-fibrinogen -455A [35].

\section{Statistical methods}

The primary hypothesis was to test whether the white cell count was elevated in OPUS TIMI-16 study ACS patients who carried pro-inflammatory genetic variants of the IL1RN and IL6 genes. This hypothesis was formulated in part because there was adequate power to detect a modest genetic effect: assuming usual allele frequencies observed in Caucasians, there is $80 \%$ power to detect a difference of 0.52 cells $/ \mathrm{mm}^{3}$ in WBC between carriers and non-carriers of the IL1RN*2 allele, and there is $80 \%$ power to detect a difference of 0.75 cells $/ \mathrm{mm}^{3}$ in WBC between the two IL6 homozygotes. Secondary analyses explored whether there were any associations between IL1RN and IL6 genotype and other inflammatory markers. Exploratory analyses investigated the roles of eight other genetic variants. The variables were summarized using box-plots that indicate the median and the $25^{\text {th }}$ and $75^{\text {th }}$ percentiles. The boxplots also include a 95\% CI for the median. Analyses in the EXCITE stable angina (SA) and EXCITE ACS patient groups were performed for comparison. For these EXCITE patients, recruitment was not restricted to around the time of an acute event, and therefore are more indicative of the counts of WBC and platelets in coronary patients who are not having acute events.

The 95\% confidence intervals for medians were estimates using a binomial method that makes no assumptions as to the underlying distribution of the variable. The 95\% confidence intervals for the difference in median WBC between genotypes were estimated using 10,000 bootstrap re-samples. Median values for each of the IL1RN and IL-6 genotypes were compared using the Kruskal-Wallis rank sum test. The associations between WBC count, 
platelet count, C-reactive protein and fibrinogen were expressed as Spearman rank correlations. The $\chi^{2}$ test was used when analyzing categorical data. An exploratory analysis of the association with eight additional genes considered carrier status for the allelic variant. Analysis was performed using the STATA (version 7.0: Statacorp, 2001) and S-Plus (version 6: Insightful Corporation, 2001) packages.

\section{Results}

Relationship among inflammation-associated measures

An increased white blood cell count (WBC) was associated with an increased (baseline) platelet count $(r=0.28$, $\mathrm{p}<0.001)$ and C-reactive protein $(\mathrm{r}=0.23, \mathrm{p}<0.001)$. There was also a positive correlation between levels of $\beta$ fibrinogen and C-reactive protein $(\mathrm{r}=0.42, \mathrm{p}<0.0001)$. Weaker associations were found between C-reactive protein and platelet count (a negative correlation, $\mathrm{r}=-0.12$, $\mathrm{p}$ $=0.05)$, and between troponin and fibrinogen $(\mathrm{r}=0.14, \mathrm{p}$ $=0.04)$.

\section{Impact of pro-inflammatory genotype upon white cell count}

The primary hypothesis that we sought to address was whether the white cell counts of ACS patients were significantly influenced by pro-inflammatory genotype. Fig. 1a indicates that the white cell counts were not influenced by either the IL1RN or their IL6 genotypes. The difference in median WBC between the two homozygote IL6 genotypes was $0.21 / \mathrm{mm}^{3}$ (95\% CI $=-0.41$ to 0.77$)$, representing only $6.3 \%$ of the inter-quartile range of WBC. The difference in median WBC between the two homozygote IL1RN genotypes was $-0.03 / \mathrm{mm}^{3}(95 \% \mathrm{CI}=-0.55$ to 0.86$)$, representing only $0.9 \%$ of the inter-quartile range. Given the relative rarity of the $* 2 /{ }^{*} 2$ genotype, we compared the IL1RN*1/*1 and $* 1 /{ }^{*} 2$ genotypes, who differ in median by $-0.23 / \mathrm{mm}^{3}(95 \% \mathrm{CI}=-0.64$ to 0.24$)$ or just $6.8 \%$ of the interquartile range.

\section{Impact of pro-inflammatory genetic variants on other inflammation associated measures}

Secondary analyses investigated the impact of the proinflammatory gene variants on other inflammatory markers and on troponin. Platelet count did not significantly differ according to IL-6 genotype (Fig. 2a). However, the IL1RN*2/*2 homozygote was associated with a reduced platelet count. This was nominally significant $(\mathrm{p}=0.002)$, and after correction for 4 pro-inflammatory genotypes and the 4 measures investigated this finding remains of borderline significance $(16$ tests, corrected $\mathrm{p}=0.03)$. No associations were found between the genotypes and CRP, $\beta$-fibrinogen or troponin levels (Figure $3 a, 3 b, 3 c$ ).

To provide an indication of the role of genetic factors versus other predictors of WBC, we considered those subjects with measured levels of CRP. CRP variability accounted for $6.5 \%$ of the variance in WBC. Only $1.2 \%$ was explained by the combined effects of IL1RN and IL6 genotypes (excluding other covariates from the model). When subjects age, sex, smoking status, BMI, and geographic location together with their levels of CRP were considered in a single regression model, the proportion of variance in WBC accounted for by these variables was 0.20 (adjusted $\mathrm{R}^{2}$ ). Addition of carrier status for the IL1RN*2 and IL6-17G genotypes led to only a marginal increase $(0.21)$, which is consistent with the findings above that the genotypes have very little effect. The combined effect of carrier status for all ten genes (see below) explained at most (estimate unadjusted for number of variables) only $4.3 \%$ of the variation in WBC.

\section{Impact of interaction between WBC and genotype on outcome}

In the OPUS TIMI-16 study, few patients had a myocardial infarction during the follow-up period. Therefore we analysed the composite endpoint, which in addition to myocardial infarction included recurrent angina requiring rehospitalisation, urgent revascularisation, death and stroke. There were relatively few of the latter two endpoints (see Shields et al 2002 for more details [35]). There were 118 composite endpoints among the 732 patients with WBC measurements at baseline. There was no significant association between elevated WBC and CRP (defined as the top quartile) and the composite endpoint (relative risk 1.0, CI 0.66-1.5 for WBC and 1.1, CI 0.7, 1.6 for CRP).

We examined whether interactions between WBC and genotype influenced the composite outcome. Of the 185 subjects with an elevated WBC count, 82 were carriers of the IL1RN*2 allele and 154 were carriers of the IL6-174G allele. The hazard ratio for composite events associated with elevated WBC count for carriers and non-carriers of the IL1RN*2 allele was $1.2(0.7,2.2)$ and $0.8(0.5,1.5)$, respectively (interaction $\mathrm{p}=0.61$, not significant) Similarly, there was no influence on outcome of interaction between WBC and the IL6-174G allele: the hazard ratio associated with elevated WBC was $1.0(0.6,1.5)$ for carriers of the IL6-174G allele and $1.1(0.4,3.0)$ for non-carriers (interaction $\mathrm{p}=0.48$ ).

30 subjects were carriers of the IL1RN*2 allele and had elevated CRP, while only 14 patients had elevated CRP and did not carry the IL6-G allele. The hazard ratio for composite events associated with elevated CRP was 1.3 $(0.7,2.2)$ for IL1-RN*2 carriers and $0.6(0.3,1.3)$ for noncarriers, which was a non-significant interaction $(\mathrm{p}=$ 0.09). Similarly the hazard ratio associated with elevated CRP was $1.1(0.7,1.8)$ for carriers and $1.0(0.4,2.7)$ for non-carriers of IL6-174G allele $(\mathrm{p}=0.89)$. Thus, patients 


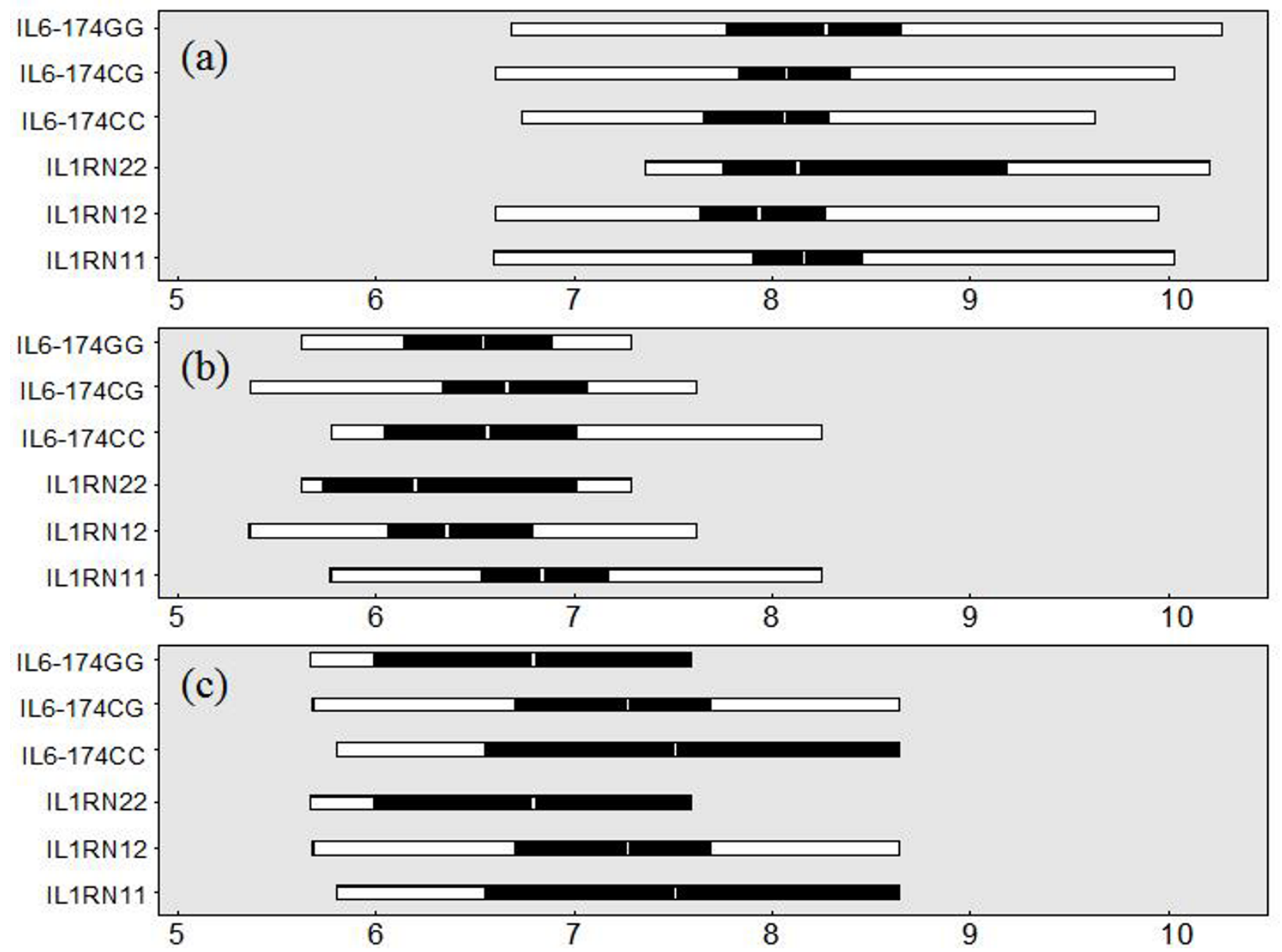

Figure I

For each of the ILIRN and IL-6 genotypes patients the median (central line) is shown. Flanking this is a dark shaded box, representing the $95 \%$ confidence interval of the median. This gives an indication of the confidence in the estimate of the median. The white boxes represent the inter-quartile range (from $25^{\text {th }}$ percentile to the $75^{\text {th }}$ percentile), giving an indication of the variability

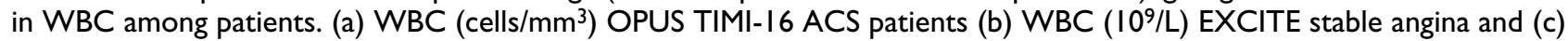
WBC (10\%/L) EXCITE ACS patient groups.

with a high CRP and particular inflammatory genotypes do not have an altered risk of composite events.

\section{Other genetic factors}

Further exploratory statistical analyses considered eight additional genes (Table 2): GPIa, GPIIIa (PlA2 variant), $\beta$ fibrinogen, MMP-9, GPIb $\alpha$, (kozak), E-selectin, P-selectin, and vWF in the OPUS-TIMI-16 population. We present these results here simply for completeness: these were mainly initially investigated in relation to their effects on thrombotic outcome, and we did not a priori anticipate that any these were likely to be associated with WBC [35]. WBC was not significantly altered by any of these variants. Platelet counts were significantly higher in carriers of the PLA2 allele (medians, 204 for non-carrier versus 215 for carriers, $\mathrm{p}=0.04$ ). This is not significant after correction for multiple testing. Platelet counts were significantly lower among carriers of the MMP-9T allele ( $p$ $=0.03$ ) and significantly higher among carriers of the Pselectin-C allele, but these results were not significant after adjustment for multiple testing.

\section{Stable angina and acute cases sampled outside timeframe} of acute event (EXCITE study)

In the EXCITE study, the WBC count was significantly higher among ACS patients than SA patients (median 7.3 


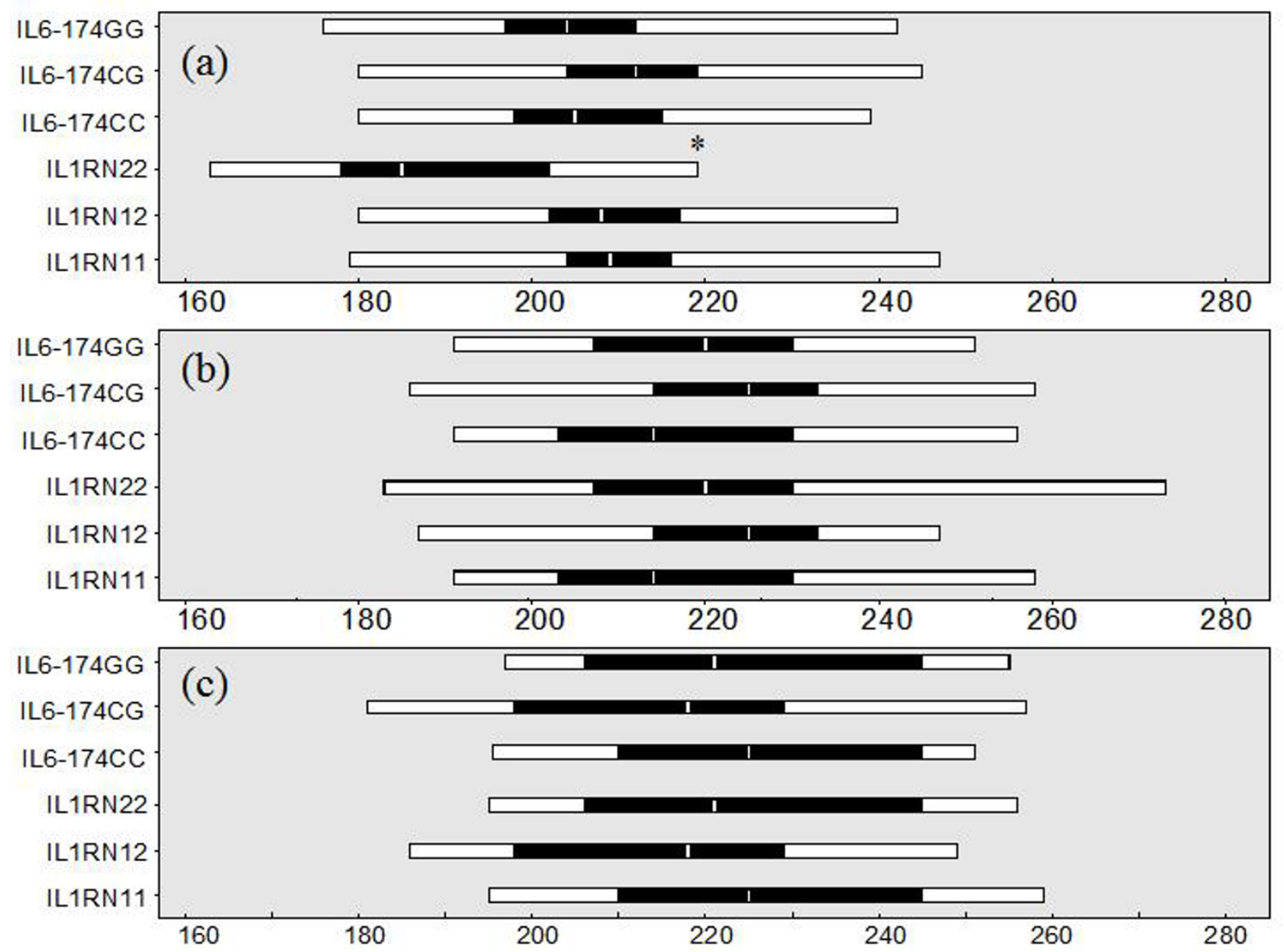

Figure 2

Platelet count (cells $/ \mathrm{mm}^{3}$ ) versus ILIRN and IL-6 genotypes for the (a) OPUS TIMI- I6, (b) Platelet count (I09/L) EXCITE stable angina and (c) Platelet count (I0\%/L) EXCITE ACS patient groups. See Fig. I for details.

vs. 6.6, $\mathrm{p}=0.02$, Table 4 ). WBC counts were clearly lower than those seen for the OPUS TIMI-16 patients, whose measurements were close to the time of acute presentation. In both groups, an increased WBC count was associated with an increased (baseline) platelet count $(\mathrm{r}=0.21$, $\mathrm{p}<0.01$ for ACS and $\mathrm{r}=0.38, \mathrm{p}<0.0001$ for SA). The platelet count did not differ significantly between the SA and ACS groups in the EXCITE study. Platelet counts were lower for the OPUS TIMI-16 patients.

In the EXCITE-ACS patients, there were no significant effects of genotype on white cell count (Fig. 1b). EXCITESA patients (Fig. 1c) had a marginally lower WBC count among carriers of the IL1RN*2 allele (medians, 6.3 among carriers versus 6.8 among non-carriers, $\mathrm{p}=0.03$; not significant after correction for multiple testing). EXCITE-ACS and EXCITE-SA groups did not show any significant effects of genotype on platelet count, including the IL1RN*2/*2 which was associated with elevated platelet count in the OPUS TIMI-16 study (Fig. 2b,2c).

Among EXCITE-ACS patients WBC counts were lower among carriers of the MMP-9T allele $(\mathrm{p}=0.01)$ and higher among carriers of $\beta$-fibrinogen -455A ( $p=0.007$ ), however, this was of borderline significance after adjustment for multiple testing ( $\mathrm{p}=0.05)$.

\section{Discussion}

Common variants of cytokine genes that are contributory factors in inflammatory conditions have also been 


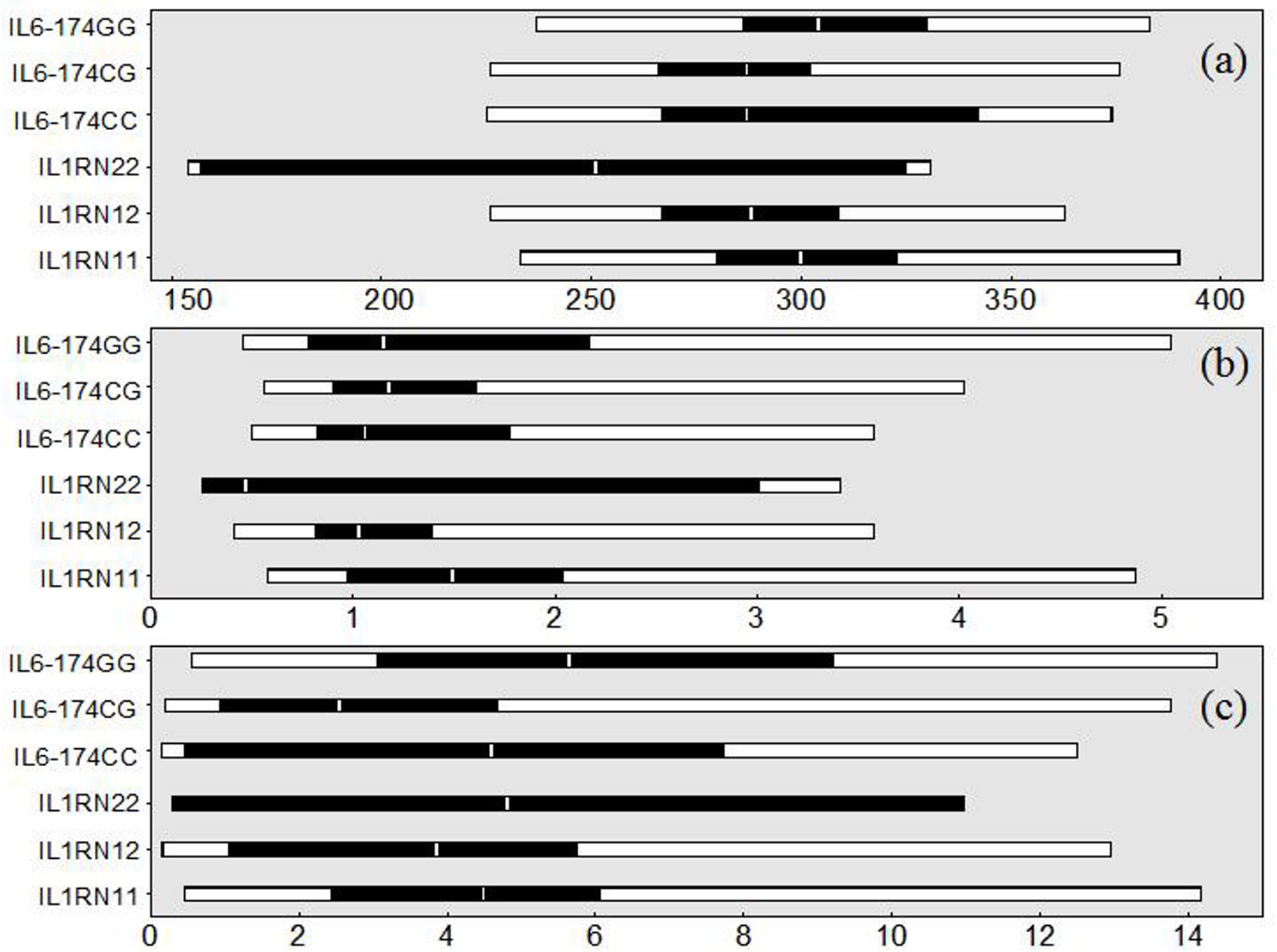

Figure 3

(a) Fibrinogen $(\mathrm{mg} / \mathrm{dl})(\mathrm{b})$, CRP $(\mathrm{mg} / \mathrm{dl})(\mathrm{c})$, troponin $(\mathrm{ng} / \mathrm{ml})$ levels versus ILIRN and IL-6 genotypes for the OPUS TIMI-I6 study. See Fig. I for details.

implicated in coronary artery disease [27]. For example, the variable number tandem repeat (VNTR) polymorphism in intron 2 of the gene for interleukin-1 receptor antagonist (IL-1RN), is elevated in patients with MI $[22,26]$. It should be emphasized however that associations of the IL-1RN-VNTR with disease may be related to either this protein or the interleukin gene cluster, in particular the IL1-beta gene, whose promoter variants are in disequilibrium with the VNTR $[21,25]$.

The VNTR polymorphism of the IL1RN gene has 5 alleles of between 2 and 6 repeats of an 86 bp sequence. The 4 repeat (IL1RN*1) and the 2 repeat sequence (IL1RN*2) are the most common while the other alleles occur at a combined frequency of $<5 \%$. One of the first studies which implicated cytokine gene variants in susceptibility to heart disease reported an association between the ${ }^{*} 2$ allele of IL1RN and single vessel coronary artery disease, although this was not confirmed in a larger prospective study $[27,28]$. There have also been reports of associations between the *2 allele of IL1RN and several other inflammatory diseases where IL-1 has been implicated have also previously been found $[23,24]$. In all of these diseases carriage of only one copy of the IL1RN*2 was sufficient to affect disease course.

A G/C polymorphism at position -174 of the interleukin6 promoter that has been associated with raised levels of IL- 6 and juvenile arthritis has also been associated with atherosclerosis [30,32]. However, we found no evidence 
Table I: OPUS TIMI-I 6 study: Correlations (r) among White Blood Cell count (WBC), Platelet count, C-reactive protein (CRP), Fibrinogen protein and troponin $\mathrm{T}$.

\begin{tabular}{lllll}
\hline & Platelet & CRP & Fibrinogen & Troponin T \\
\hline WBC & $0.28(<0.0001)$ & $0.23(0.0003)$ & $0.10(0.13)$ & $0.29(0.0001)$ \\
Platelet & & $-0.12(0.05)$ & $0.02(0.78)$ & $-0.04(0.55)$ \\
CRP & & $0.42(<0.0001)$ & $0.41(<0.0001)$ & $0.14(0.04)$ \\
Fibrinogen & & & \\
\hline
\end{tabular}

IValues are for measurements made at time of recruitment in the OPUS TIMI-I6 study. P-values are shown in parentheses.

Table 2: OPUS TIMI-16 study: Distribution of genotypes n (\%)

\begin{tabular}{llll}
\hline & Zero & One & Two \\
\hline ILIRN*2 & $510(55.2)$ & $354(38.3)$ & $60(6.5)$ \\
IL6-174G & $180(19.5)$ & $466(50.5)$ & $276(29.9)$ \\
GPla 807T & $315(34.1)$ & $449(48.6)$ & $160(17.3)$ \\
GPIIla PLA2 & $680(73.6)$ & $222(24.0)$ & $37(2.4)$ \\
Fibrinogen -455A & $587(63.6)$ & $299(32.4)$ & $18(2.0)$ \\
MMP9-1562T & $660(71.4)$ & $246(26.6)$ & $12(1.3)$ \\
GPIba-5T & $711(77.0)$ & $200(21.7)$ & $10(1.1)$ \\
E-selectin I28C & $731(79.2)$ & $182(19.7)$ & $9(1.0)$ \\
P-selectin 7I5C & $746(81.0)$ & $166(18.0)$ & $125(13.6)$ \\
vWF-I05IG & $381(41.3)$ & $416(45.1)$ & \\
\hline
\end{tabular}

Table 3: EXCITE study: Distribution of genotypes n (\%)

\begin{tabular}{llll}
\hline & Zero & One & Two \\
\hline $\begin{array}{l}\text { Stable } \\
\text { ILIRN*2 }\end{array}$ & $193(56.6)$ & $125(36.7)$ & $23(6.7)$ \\
IL6-174G & $58(17.0)$ & $168(49.1)$ & $116(33.9)$ \\
ACS & & & $16(8.5)$ \\
ILIRN*2 & $93(49.2)$ & $80(42.3)$ & $59(31.2)$ \\
IL6-174G & $35(18.5)$ & $95(50.3)$ &
\end{tabular}

Table 4: OPUS TIMI-I6 study: WBC Median (QI, Q3)

\begin{tabular}{|c|c|c|c|}
\hline Gene & Zero & One & Two \\
\hline \multicolumn{4}{|l|}{ OPUS } \\
\hline ILIRN*2 & $8.2(6.6,10.0)$ & $7.9(6.6,10.0)$ & $8.1(7.4,10.2)$ \\
\hline IL6-I74G & $8.1(6.7,9.6)$ & $8.1(6.6,10.0)$ & $8.3(6.7,10.3)$ \\
\hline \multicolumn{4}{|l|}{ EXCITE Stable } \\
\hline ILIRN*2 & $6.8(5.8,8.3)$ & $6.4(5.4,7.6)$ & $6.2(5.6,7.3)$ \\
\hline IL6-I74G & $6.6(5.3,7.5)$ & $6.7(5.7,8.2)$ & $6.5(5.4,8.1)$ \\
\hline All genotypes & \multicolumn{3}{|c|}{$6.6(5.6-7.9)$} \\
\hline \multicolumn{4}{|l|}{ EXCITE ACS } \\
\hline ILIRN*2 & $7.1(5.8,8.6)$ & $7.5(5.7,8.6)$ & $6.3(5.7,7.3)$ \\
\hline IL6-I74G & $7.5(5.8,8.8)$ & $7.3(5.8,8.7)$ & $6.8(5.7,8.3)$ \\
\hline All genotypes & \multicolumn{3}{|c|}{$7.3(5.8,8.6)$} \\
\hline
\end{tabular}


Table 5: OPUS TIMI-I6 study: Platelet count median (QI, Q3).

\begin{tabular}{llll}
\hline Gene & Zero & One & Two \\
\hline $\begin{array}{l}\text { OPUS } \\
\text { ILIRN*2 }\end{array}$ & & $208(180,242)$ & $185(163,219)$ \\
IL6-I74G & $209(179,247)$ & $212(180,245)$ & $204(176,242)$ \\
EXCITE Stable & $205(180,239)$ & $219(187,247)$ & $229(183,273)$ \\
ILIRN*2 & $233(191,258)$ & $225(186,258)$ & $220(191,25 I)$ \\
IL6-I74G & $214(191,256)$ & & $217(195,256)$ \\
EXCITE ACS & & $217(186,249)$ & $221(197,255)$ \\
ILIRN*2 & $299(195,259)$ & $218(181,257)$ &
\end{tabular}

Table 6: OPUS IMII6 study: Median (QI, Q3) values for fibrinogen, CRP, and Troponin T.

\begin{tabular}{llll}
\hline Gene & Zero & One & Two \\
\hline ILIRN*2 & & & $251(154,331)$ \\
Fibrinogen & $300(233,390)$ & $288(226,363)$ & $0.5(0.3,3.4)$ \\
CRP & $1.5(0.6,4.9)$ & $3.0(0.4,3.6)$ & $4.8(0.4,8.4)$ \\
Troponin & $4.5(0.5,14.2)$ & & $304(237,383)$ \\
IL6-I74G & & $287(226,376)$ & $1.2(0.5,5.0)$ \\
Fibrinogen & $287(225,374)$ & $1.2(0.6,4.0)$ & $5.7(0.6,14.4)$ \\
CRP & $1.1(0.5,3.6)$ & $2.5(0.2,13.8)$ & \\
Troponin & $4.6(0.1,12.5)$ & & \\
\hline
\end{tabular}

that this variant influenced WBC or CRP in the OPUS TIMI-16 patients with ACS. A similar lack of association was observed in a smaller study of 111 patients with coronary artery disease [29].

As the relationship between inflammatory markers and ACS disease state and thrombotic disease outcome is likely to be complex, we explored for multiple gene/markers interactions. We found no association between WBC and pro-inflammatory cytokine genotypes of the IL1RN and IL6 genes. Since these variants appear to contribute to pro-inflammatory non-cardiovascular diseases, and possibly also to atherosclerotic disease, this finding is of some interest. Since the genotypes did not determine the levels of the acute phase reactants CRP, it is plausible that the pro-inflammatory state seen in ACS patients is not dependent on the IL1-IL6 cytokine pathways. It may instead be a reaction to systemic atherosclerosis and inflammation in regions of myocardial ischaemia, although the extent of ischaemia has not been found to strongly predict the degree of WBC elevation [5]. Polymorphism in the CRP gene influencing CRP level does not appear to impact upon CHD [36]. Again, this suggests that WBC and CRP may reflect, rather than cause, the disease states. Future large studies with measurements of WBC and troponin before and after acute events may provide a better indication of whether genetic factors may interact with myocardial necrosis.

Negative findings such as this one are only valuable when the sample size has sufficient power to estimate the confidence that a certain risk is unlikely to be conferred. For the IL- 6 variant, the difference in median WBC count between the two homozygotic IL6 genotypes is estimated to range between -0.41 and +0.71 (95\% confidence interval). This range only represents approximately $1 \%$ of the interquartile range of the WBC variable. Thus, we are confident in concluding that the genotype is very unlikely to have a clinically relevant impact on the variation in WBC, and this study has good power to make this conclusion. We are equally confident in our conclusion that IL1RN genotype has little effect on WBC in the OPUS TIMI-16 study population around the time of acute presentation.

Inflammatory and thrombotic mechanisms have common components and are closely related. Therefore, we examined for the effects on markers of inflammation of both inflammatory and thrombotic genes. While a previous smaller study found an association between platelet count and IL6 genotype in healthy subjects, we failed to observe any such association in the large ACS population of the OPUS TIMI-16 study [37]. Instead we found suggestive evidence that IL1RN 2/2 genotype is associated with a 
lower platelet count. Further analyses are required in a separate and larger population to confirm this result. Interleukin- $1 \beta$ is the product of one of the genes in the IL1RN-VNTR associated gene cluster, and it may play a role in platelet function, since it is translationally up-regulated in activated platelets [21,38].

Finally, it must be pointed out that the findings of this study within the OPUS TIMI-16 trial relate only to patients recently diagnosed with a recent acute coronary event. This may not relate to the potential relationship among pro-inflammatory variants and WBC in other contexts, such as normal cohorts or cohorts exposed to infection.

\section{Conclusions}

We conclude that cytokine pro-inflammatory genetic variants, which have an impact on inflammatory disease processes do not markedly influence the inflammatory profile of patients presenting with ACS. The cytokine pathways may therefore not be pivotal determinants of the increased level of inflammatory activity in these patients.

\section{Abbreviations}

ACS: Acute coronary syndromes, AMI: Acute myocardial Infarction, CHD: Coronary heart disease, CRP: C-reactive protein, IL-1: Interleukin-1, IL-6: Interleukin-6, IL-1RN: Interleukin-1 receptor antagonist, SA: Stable angina, WBC: White blood cell count.

\section{Author's contributions}

Byrne, CE: Writing manuscript and genotyping.

Fitzgerald, A: Statistical modeling and interpretation.

Cannon CP: CRP data interpretation and clinical interpretation.

Fitzgerald, DJ: Clinical interpretation and manuscript writing.

Shields, DC: Overall hypothesis formulation and manuscript writing.

\section{Acknowledgements}

We thank the OPUS-TIMI 16 investigators for contributing to this study. This work was supported by the HEA through the Programme for Research in the Third Level Institutions award to the Institute of Biopharmaceutical Sciences, and by Searle Inc.

\section{References}

I. Yudkin JS, Kumari M, Humphries SE, Mohamed-Ali V: Inflammation, obesity, stress and coronary heart disease: is interleukin-6 the link? Atherosclerosis 2000, I 48:209-2।4.

2. Lowe GD, Machado SG, Krol WF, Barton BA, Forbes CD: White blood cell count and haematocrit as predictors of coronary recurrence after myocardial infarction. Thromb Haemost 1985 , 54:700-703.

3. Burr ML, Holliday RM, Fehily AM, Whitehead PJ: Haematological prognostic indices after myocardial infarction: evidence from the diet and reinfarction trial (DART). Eur Heart J 1992, 13:166-170.

4. Cannon CP, McCabe CH, Wilcox RG, Bentley JH, Braunwald E: Association of white blood cell count with increased mortality in acute myocardial infarction and unstable angina pectoris. OPUS-TIMI I6 Investigators. Am J Cardiol 200 I, 87:636-9, Al0.

5. Barron HV, Cannon CP, Murphy SA, Braunwald E, Gibson CM: Association between white blood cell count, epicardial blood flow, myocardial perfusion, and clinical outcomes in the setting of acute myocardial infarction: a thrombolysis in myocardial infarction 10 substudy. Circulation 2000, 102:2329-2334.

6. Volpato S, Guralnik JM, Ferrucci L, Balfour J, Chaves P, Fried LP, Harris TB: Cardiovascular disease, interleukin-6, and risk of mortality in older women: the women's health and aging study. Circulation 200I, 103:947-953.

7. Rosalki SB: C-reactive protein. Int J Clin Pract 200I, 55:269-270.

8. Berk BC, Weintraub WS, Alexander RW: Elevation of C-reactive protein in "active" coronary artery disease. Am J Cardiol 1990, 65: $168-172$.

9. Liuzzo G, Biasucci LM, Rebuzzi AG, Gallimore JR, Caligiuri G, Lanza GA, Quaranta G, Monaco C, Pepys MB, Maseri A: Plasma protein acute-phase response in unstable angina is not induced by ischemic injury. Circulation 1996, 94:2373-2380.

10. Liuzzo G, Biasucci LM, Gallimore JR, Grillo RL, Rebuzzi AG, Pepys $M B$, Maseri $A$ : The prognostic value of $C$-reactive protein and serum amyloid a protein in severe unstable angina. $N$ Engl J Med 1994, 33 I:417-424.

II. Haverkate F, Thompson SG, Pyke SD, Gallimore JR, Pepys MB: Production of $C$-reactive protein and risk of coronary events in stable and unstable angina. European Concerted Action on Thrombosis and Disabilities Angina Pectoris Study Group. Lancet 1997, 349:462-466.

12. Zebrack JS, Anderson JL, Maycock CA, Horne BD, Bair TL, Muhlestein JB: Usefulness of high-sensitivity C-reactive protein in predicting long-term risk of death or acute myocardial infarction in patients with unstable or stable angina pectoris or acute myocardial infarction. Am J Cardiol 2002, 89: I 45-I 49.

13. Toss H, Gnarpe J, Gnarpe H, Siegbahn A, Lindahl B, Wallentin L: Increased fibrinogen levels are associated with persistent Chlamydia pneumoniae infection in unstable coronary artery disease. Eur Heart J 1998, 19:570-577.

14. Levenson J, Giral P, Razavian M, Gariepy J, Simon A: Fibrinogen and silent atherosclerosis in subjects with cardiovascular risk factors. Arterioscler Thromb Vasc Biol 1995, 15:1263-1 268.

15. Tracy RP, Bovill EG, Yanez D, Psaty BM, Fried LP, Heiss G, Lee M, Polak JF, Savage PJ: Fibrinogen and factor VIII, but not factor VII, are associated with measures of subclinical cardiovascular disease in the elderly. Results from The Cardiovascular Health Study. Arterioscler Thromb Vasc Biol 1995, 15: I 269-1279.

16. Keightley AM, Lam YM, Brady JN, Cameron CL, Lillicrap D: Variation at the von Willebrand factor (vWF) gene locus is associated with plasma vWF:Ag levels: identification of three novel single nucleotide polymorphisms in the vWF gene promoter. Blood 1999, 93:4277-4283.

17. Yarnell JW, Baker IA, Sweetnam PM, Bainton D, O'Brien JR, Whitehead PJ, Elwood PC: Fibrinogen, viscosity, and white blood cell count are major risk factors for ischemic heart disease. The Caerphilly and Speedwell collaborative heart disease studies. Circulation 1991, 83:836-844.

18. Panichi V, Migliori M, De Pietro S, Taccola D, Andreini B, Metelli MR, Giovannini L, Palla R: The link of biocompatibility to cytokine production. Kidney Int Suppl 2000, 76:596-103.

19. Benderly M, Graff E, Reicher-Reiss H, Behar S, Brunner D, Goldbourt $\mathrm{U}$ : Fibrinogen is a predictor of mortality in coronary heart disease patients. The Bezafibrate Infarction Prevention (BIP) Study Group. Arterioscler Thromb Vasc Biol 1996, 16:35I-356.

20. Huber SA, Sakkinen P, Conze D, Hardin N, Tracy R: Interleukin-6 exacerbates early atherosclerosis in mice. Arterioscler Thromb Vasc Biol 1999, 19:2364-2367.

21. El-Omar EM, Carrington M, Chow WH, McColl KE, Bream JH, Young HA, Herrera J, Lissowska J, Yuan CC, Rothman N, Lanyon G, Martin 
M, Fraumeni J. F., Jr., Rabkin CS: Interleukin-I polymorphisms associated with increased risk of gastric cancer. Nature 2000, 404:398-402.

22. Tarlow JK, Blakemore Al, Lennard A, Solari R, Hughes HN, Steinkasserer A, Duff GW: Polymorphism in human IL-I receptor antagonist gene intron 2 is caused by variable numbers of an 86-bp tandem repeat. Hum Genet 1993, 91:403-404.

23. Cork MJ, Tarlow JK, Clay FE, Crane A, Blakemore AI, McDonagh AJ, Messenger AG, Duff GW: An allele of the interleukin-I receptor antagonist as a genetic severity factor in alopecia areata. J Invest Dermatol 1995, 104: 15S-16S.

24. Blakemore Al, Cox A, Gonzalez AM, Maskil JK, Hughes ME, Wilson RM, Ward JD, Duff GW: Interleukin-I receptor antagonist allele (ILIRN*2) associated with nephropathy in diabetes mellitus. Hum Genet 1996, 97:369-374.

25. Witkin SS, Gerber S, Ledger WJ: Influence of interleukin-I receptor antagonist gene polymorphism on disease. Clin Infect Dis 2002, 34:204-209.

26. Shibata M, Endo S, Inada K, Kuriki S, Harada M, Takino T, Sato N, Arakawa N, Suzuki T, Aoki H, Hiramori K: Elevated plasma levels of interleukin-I receptor antagonist and interleukin- 10 in patients with acute myocardial infarction. J Interferon Cytokine Res 1997, 17: I45-150.

27. Francis SE, Camp NJ, Dewberry RM, Gunn J, Syrris P, Carter ND, Jeffery S, Kaski JC, Cumberland DC, Duff GW, Crossman DC: Interleukin-I receptor antagonist gene polymorphism and coronary artery disease. Circulation 1999, 99:861-866.

28. Zee RY, Lunze K, Lindpaintner K, Ridker PM: A prospective evaluation of the interleukin-I receptor antagonist intron 2 gene polymorphism and the risk of myocardial infarction. Thromb Haemost 200I, 86: I|4I-II43.

29. Burzotta F, lacoviello L, Di Castelnuovo A, Glieca F, Luciani N, Zamparelli R, Schiavello R, Donati MB, Maseri A, Possati G, Andreotti F: Relation of the $-174 \mathrm{G} / \mathrm{C}$ polymorphism of interleukin-6 to interleukin-6 plasma levels and to length of hospitalization after surgical coronary revascularization. Am J Cardiol 200I, 88: I |25-II 28

30. Fishman D, Faulds G, Jeffery R, Mohamed-Ali V, Yudkin JS, Humphries $S$, Woo $P$ : The effect of novel polymorphisms in the interleukin-6 (IL-6) gene on IL-6 transcription and plasma IL-6 levels, and an association with systemic-onset juvenile chronic arthritis. J Clin Invest 1998, I02:1369-1376.

31. Foster CB, Lehrnbecher T, Samuels S, Stein S, Mol F, Metcalf JA, Wyvill K, Steinberg SM, Kovacs J, Blauvelt A, Yarchoan R, Chanock SJ: An IL6 promoter polymorphism is associated with a lifetime risk of development of Kaposi sarcoma in men infected with human immunodeficiency virus. Blood 2000, 96:2562-2567.

32. Rauramaa R, Vaisanen SB, Luong LA, Schmidt-Trucksass A, Penttila IM, Bouchard C, Toyry J, Humphries SE: Stromelysin-I and interleukin-6 gene promoter polymorphisms are determinants of asymptomatic carotid artery atherosclerosis. Arterioscler Thromb Vasc Biol 2000, 20:2657-2662.

33. Cannon CP, McCabe CH, Wilcox RG, Langer A, Caspi A, Berink P, Lopez-Sendon J, Toman J, Charlesworth A, Anders RJ, Alexander JC, Skene A, Braunwald E: Oral glycoprotein Ilb/IIla inhibition with orbofiban in patients with unstable coronary syndromes (OPUS-TIMI 16) trial. Circulation 2000, 102:149-156.

34. O'Neill WW, Serruys P, Knudtson M, van Es GA, Timmis GC, van der Zwaan C, Kleiman J, Gong J, Roecker EB, Dreiling R, Alexander J, Anders R: Long-term treatment with a platelet glycoproteinreceptor antagonist after percutaneous coronary revascularization. EXCITE Trial Investigators. Evaluation of Oral Xemilofiban in Controlling Thrombotic Events. N Engl J Med 2000, 342:1316-1324.

35. Shields DC, Fitzgerald AP, O'Neill PA, Muckian C, Kenny D, Moran B, Cannon CP, Byrne CE, Fitzgerald DJ: The contribution of genetic factors to thrombotic and bleeding outcomes in coronary patients randomised to Ilb/llla antagonists. Pharmacogenomics J 2002, 2:182-190.

36. Zee RY, Ridker PM: Polymorphism in the human C-reactive protein (CRP) gene, plasma concentrations of CRP, and the risk of future arterial thrombosis. Atherosclerosis 2002, 162:217-219.

37. Fernandez-Real JM, Vendrell J, Richart C, Gutierrez C, Ricart W: Platelet count and Interleukin 6 Gene polymorphism in healthy subjects. BMC Med Genet 200I, 2:6-9.
38. Lindemann S, Tolley ND, Dixon DA, McIntyre TM, Prescott SM, Zimmerman GA, Weyrich AS: Activated platelets mediate inflammatory signaling by regulated interleukin Ibeta synthesis. J Cell Biol 200I, I 54:485-490.

\section{Pre-publication history}

The pre-publication history for this paper can be accessed here:

http://www.biomedcentral.com/1471-2350/5/13/prepub
Publish with Biomed Central and every scientist can read your work free of charge

"BioMed Central will be the most significant development for disseminating the results of biomedical research in our lifetime. "

Sir Paul Nurse, Cancer Research UK

Your research papers will be:

- available free of charge to the entire biomedical community

- peer reviewed and published immediately upon acceptance

- cited in PubMed and archived on PubMed Central

- yours - you keep the copyright

Submit your manuscript here:

http://www.biomedcentral.com/info/publishing_adv.asp
BiolMedcentral 